\title{
DÜBLIN
}

Technological University Dublin

ARROW@TU Dublin

\section{Dielectric and Optical Study of Biaxial Bent-Core Nematic Liquid Crystal}

\author{
S. P. Sreenilayam \\ Technological University Dublin \\ M. Nagaraj \\ Trinity College Dublin, Ireland \\ Yuri Panarin \\ Technological University Dublin, yuri.panarin@tudublin.ie
}

See next page for additional authors

Follow this and additional works at: https://arrow.tudublin.ie/engscheleart2

Part of the Electrical and Computer Engineering Commons

\section{Recommended Citation \\ Keith, C. et al. (2011). Dielectric and optical study of biaxial bent-core nematic liquid crystal. Molecular Crystals and Liquid Crystals vol. 540, pp. 75-81. DOI:10.1080/15421406.2011.568335}

This Article is brought to you for free and open access by the School of Electrical and Electronic Engineering at ARROW@TU Dublin. It has been accepted for inclusion in Articles by an authorized administrator of ARROW@TU Dublin. For more information, please contact arrow.admin@tudublin.ie, aisling.coyne@tudublin.ie, gerard.connolly@tudublin.ie.

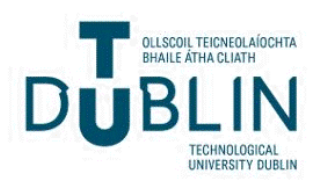




\section{Authors}

S. P. Sreenilayam, M. Nagaraj, Yuri Panarin, J. K. Vij, C. Keith, and C. Tschierske

This article is available at ARROW@TU Dublin: https://arrow.tudublin.ie/engscheleart2/163 


\title{
Dielectric and Optical Study of Biaxial Bent-Core Nematic Liquid Crystal
}

\author{
S. P. SREENILAYAM, ${ }^{1}$ M. NAGARAJ ${ }^{2}$ \\ Y. P. PANARIN,${ }^{1,2}$ J. K. VIJ, ${ }^{2}$ C. KEITH,${ }^{3}$ AND \\ C. TSCHIERSKE ${ }^{3}$ \\ ${ }^{1}$ School of Electronic \& Communication Engineering, Dublin Institute of \\ Technology, Dublin, Ireland \\ ${ }^{2}$ Department of Electronic and Electrical Engineering, Trinity College \\ Dublin, Dublin, Ireland \\ ${ }^{3}$ Institute of Organic Chemistry, Martin Luther-University \\ Halle-Wittenberg, Germany
}

\begin{abstract}
We report the observation of biaxial nematic phase in a bent-core molecular system in which the biaxiality exists on a microscopic scale using polarizing microscopy, electro-optics and dielectric spectroscopy. An application of electric field induces a macroscopic biaxiality and therefore electro-optic switching. The observed electro-optic switching is explained in terms of the interaction of the ferroelectric clusters with the electric field. Dielectric spectra of the sample shows existence of low-frequency collective processes related to the microscopic polar clusters. The dielectric constant changes its sign from positive to negative and again to positive values.
\end{abstract}

Keywords Bent-core molecules; biaxial nematic; dielectric relaxation; electrooptic effects; molecular and collective processes

\section{Introduction}

Based on generalised Maier-Saupe theory, Freiser [1] predicted that a reduction in molecular symmetry could lead to the formation of a new, biaxial nematic phase $\left(\mathrm{N}_{\mathrm{b}}\right)$ in addition to the observed uniaxial nematic phase. Biaxial nematic LC has a secondary director $\boldsymbol{m}$ perpendicular to the primary director $\boldsymbol{n}$; the latter is always prevalent in the nematic phase. From a practical point of view, the switching of the secondary director is at least a factor of 100 faster than of the primary one. Therefore such biaxial nematics with an improved response offer significant advantages over the conventional nematics in applications for fast displays and photonic devices. The potential for faster devices has led to a significantly increased interest in theoretical, experimental and computational studies on the biaxial nematic phase.

Address correspondence to J. K. Vij, Department of Electronic and Electrical Engineering, Trinity College Dublin, Dublin 2, Ireland. Tel.: +353-1-896-1431; Fax: +353-1-677-2442; E-mail: jvij@tcd.ie 
The first experimental proof for the existence of the $\mathrm{N}_{\mathrm{b}}$ phase in a lyotropic liquid crystal system was reported in 1980 [2]. But the existence of $\mathrm{N}_{\mathrm{b}}$ phase in thermotropic liquid crystal system has been a controversial issue [3-6] over several years. The thermotropic biaxial nematic phase was finally discovered in 2004 in liquid crystalline polymers [7], organo-siloxane tetrapodes [8,9], and in low molar mass bent-core systems [10-12]. A possibility for the existence of a biaxial nematic phase has been supported by numerous theoretical studies over the last decade in biaxial parallelepiped shaped (or board or brick-like) molecules [13-15] and also in bent-core systems [16-18].

In bent-core systems, due to the $\mathrm{C}_{2 \mathrm{v}}$ symmetry and the existence of large transverse dipole moment gives rise to unusually strong intermolecular interactions that lead to the formation of ferroelectric domains or clusters [19] which were experimentally confirmed by several studies [20-27]. It is still not clear whether such nematic liquid crystal comprised of distinguishable clusters of a lower symmetry phase, or there are correlated regions having short-range order like the long-range order of the lower temperature phase. On applying the electric field, the collective alignment of domains leads to a macroscopically biaxial ordering [23]. On removal of the field the domains are destabilized, with a corresponding drop in the biaxial order parameter. Recently the fast electrooptic effect due to the induced biaxiality successfully demonstrated and studied [27].

In spite of the obvious progress made in both the experimental and theoretical studies, a number of problems still remain to be solved [28] and therefore the subject of biaxial nematics continues to be a highly debated and challenging in the field of liquid crystals.

In this paper we report the results of experimental study of bent-core biaxial nematic compound by electro-optics and dielectric spectroscopy. The observed experimental results are explained in terms of the interaction of the ferroelectric clusters with the electric field.

\section{Experimental Methods}

The bent-core LC sample under study, $\mathrm{C}_{6}$-BAN, is synthesized in Halle, Germany [27]. The molecular structure of the studied material is given in Figure 1.

A particular nematic phase, to be discussed below, is found to exhibit biaxial properties under certain conditions. For the optical and electro-optical studies the compound was filled in homeotropically-aligned cells of different thickness varying from 4 to $50 \mu \mathrm{m}$. The foil stripes of different thickness were used as electrodes in order to apply the external electric field parallel to the plane of the glass plates.

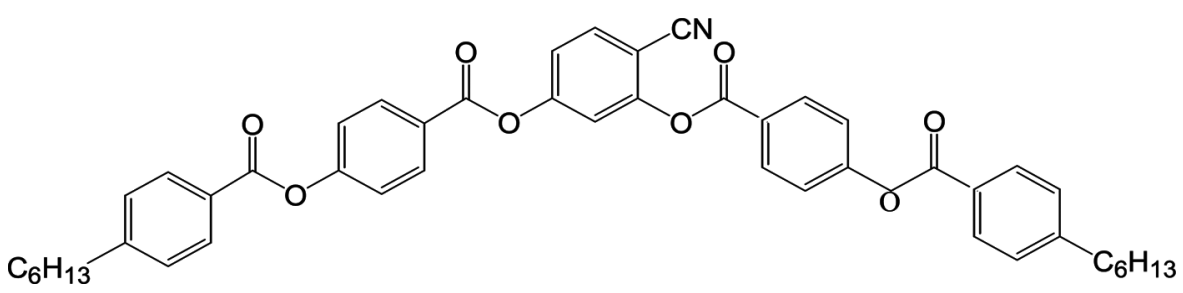

Figure 1. Molecular structure of $\mathrm{C}_{6}$-BAN compound. 
The gap between the electrodes was about $\sim 200 \mu \mathrm{m}$. AL60702 (JSR Micro Korea) polymer was used to achieve the homeotropic alignment.

The dielectric study was performed using a broadband high resolution dielectric spectrometer (Novocontrol GmbH, Germany) on planar and homeotropic cells of $9 \mu \mathrm{m}$ thickness. The ITO coated glass plates were used as electrodes. Homeotropic alignment was achieved by using AL60702 and the planar alignment by using polyamide.

The textures in these samples are strongly affected by the surfaces. On cooling from the isotropic to nematic phase in a thick $(50 \mu \mathrm{m})$ cell, the nematic phase is found to consist of only two-brush Schlieren texture which hints the presence of biaxial nematic phase. Nevertheless, this texture is not stable in time and within one hour it transforms to rather uniform while not perfectly dark texture. The thin $(4 \mu \mathrm{m})$ cell finally produces a perfect high-extinction homeotropic alignment.

The magnitude of induced biaxiality was measured using a tilting optical compensator inserted into the polarising microscope. This allows one to measure rather small values of the optical retardation for a particular region of the cell, which in our case is the centre between the foil electrodes.

\section{Results and Discussion}

\subsection{Electro-Optic Effect in Homeotropic Cell}

The effect of electric field on the textures was studied in a $4 \mu \mathrm{m}$ cell with foil spacers as electrodes. A square-wave field $100 \mathrm{~Hz}$ is applied across the electrodes in the plane of a glass plates. The cell was placed between the crossed polarizers with the angle of $45^{\circ}$ between the electric field and polarizer axis. Initially for rather small electric field $(<0.3 \mathrm{~V} / \mu \mathrm{m})$ there is no significant effect observed and the LC remains optically uniaxial. On application of stronger electric field the cell shows electro optical switching from dark to bright state and vice versa on the field removal (Fig. 2).

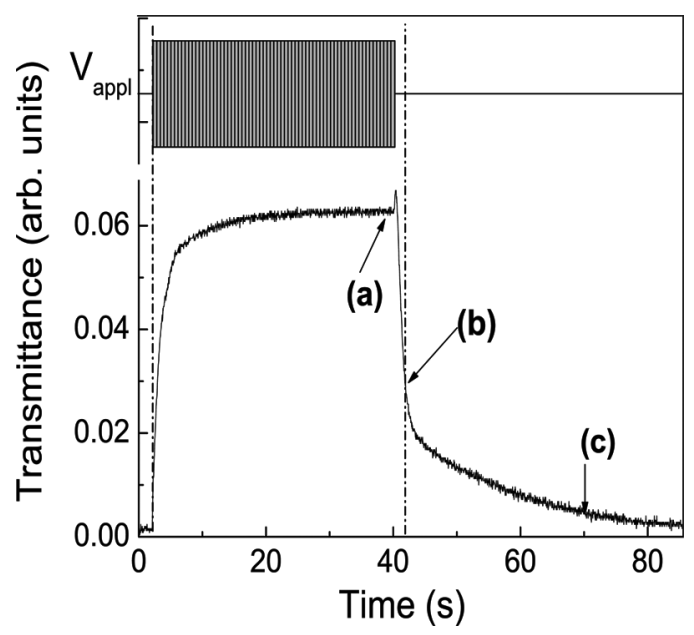

Figure 2. Electrooptic response in a $4-\mu \mathrm{m}$ homeotropic cell at $\mathbf{E}=1 \mathrm{~V} / \mu \mathrm{m}, 100 \mathrm{~Hz}, \mathrm{~T}=106^{\circ} \mathrm{C}$. 

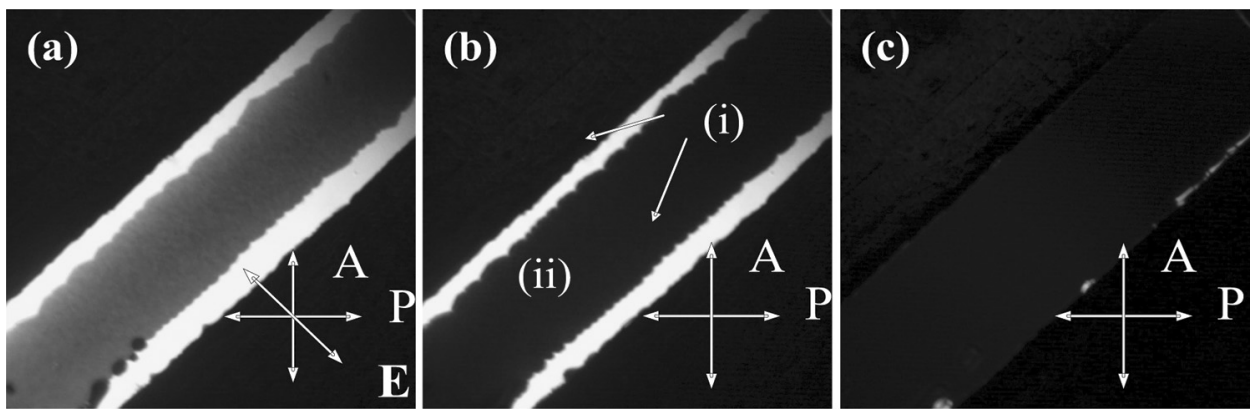

Figure 3. Dynamics of induced biaxiality (a) at $\mathbf{E}=0.5 \mathrm{~V} / \mu \mathrm{m}$. (b) and (c) are obtained $1 \mathrm{~s}$ and $30 \mathrm{~s}$ after field removal. $\mathrm{T}=106{ }^{\circ} \mathrm{C}, \mathrm{A}, \mathrm{P}, \mathbf{E}$ are directions of analyzer, polarizer and electric field.

The electrooptic response consists of two dynamics: slow and fast, suggesting the coexistence of two different processes. This suggestion is supported by polarizing microscopy observations (Fig. 3). Figure 3(a) shows the texture at applied $0.5 \mathrm{~V} / \mu \mathrm{m}$ electric field. After the field is removed, the cell relaxes to an apparently initial macroscopically uniaxial state (Fig. 3(c)). The texture of the cell consists of two distinct regions: (i) two bright stripes near the electrodes with slow dynamics $(\sim 10 \mathrm{~s})$, and (ii) a uniform dark region between the two bright strips with fast dynamics ( $\sim 1 \mathrm{~ms}$ ) (see Fig. 3); a sharp border between the two regions is clearly seen. At this stage, we summarise that the first (i) high-birefringent stripe region is the field induced planar (or tilt) alignment and the second (ii) region is due to the field-induced biaxiality due to aligning of the clusters short axes. The fast electrooptic effect has a certain potential in display application due to fast high-contrast (Figs. 2, 3) response. The parasitic slow response reduces the contrast ratio and switching speed and can be removed by using molecules with strong negative dielectric anisotropy.

\subsection{Dielectric Spectroscopy}

The dielectric study was performed on planar and homeotropic cells of $9 \mu \mathrm{m}$ thickness using broadband high resolution dielectric spectrometer (Novocontrol $\mathrm{GmbH}$, Germany). Experiments are carried out in the frequency range $1 \mathrm{~Hz}-10 \mathrm{MHz}$ on cooling the sample from $115^{\circ} \mathrm{C}$ to $60^{\circ} \mathrm{C}$.

Figure 4 shows dielectric loss spectra $\left(\varepsilon^{\prime \prime}\right)$ for both planar and homeotropic cells. There are at least two interesting features which are not observed in conventional nematic systems. The first one is a relatively small difference in the relaxation frequencies on molecular relaxation processes around short and long molecular axes. This can be understood by a smaller difference in the molecular sizes along and perpendicular the long molecular axis compare to purely calamitic LCs.

The second feature is an existence of low frequency relaxation processes in both samples with the relaxation frequencies of 2-3 orders less than the frequencies of the corresponding molecular modes. These low-frequency dielectric relaxation processes may be connected with fluctuations of ferroelectric clusters. The existence of these relaxation processes is responsible for unusual frequency behavior of the dielectric anisotropy. 

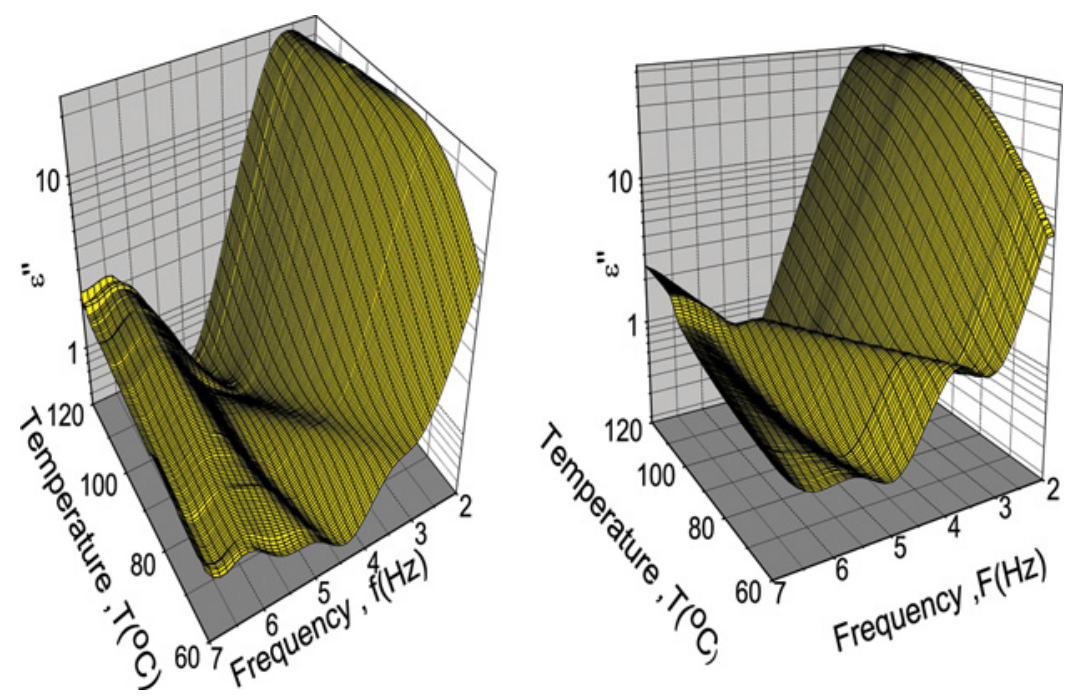

Figure 4. Temperature dependence of dielectric loss spectra $\left(\varepsilon^{\prime \prime}\right)$ in (a) $7.8 \mu \mathrm{m}$ planar and (b) $12 \mu \mathrm{m}$ homeotropic cells. (Figure appears in color online.)

Figure 5 presents the frequency dependence of the dielectric constants, $\varepsilon_{\perp}$ and $\varepsilon_{\|}$ measured in correspondingly planar $\left(\varepsilon_{\perp}\right)$ and homeotropic $\left(\varepsilon_{\|}\right)$cells and their difference $\Delta \varepsilon=\varepsilon_{\|}-\varepsilon_{\perp}$.

Here again one can find two new features compared to ordinary nematics. The first one is the existence of two sign inversion points of the dielectric anisotropy at $25 \mathrm{kHz}$ and $1 \mathrm{MHz}$. Secondly, a relatively low relaxation frequency of the first sign inversion point, i.e., $25 \mathrm{kHz}$ at $100^{\circ} \mathrm{C}$, which can be as low as $1 \mathrm{kHz}$ at room temperature. This may be useful for double-frequency control of nematic displays, where

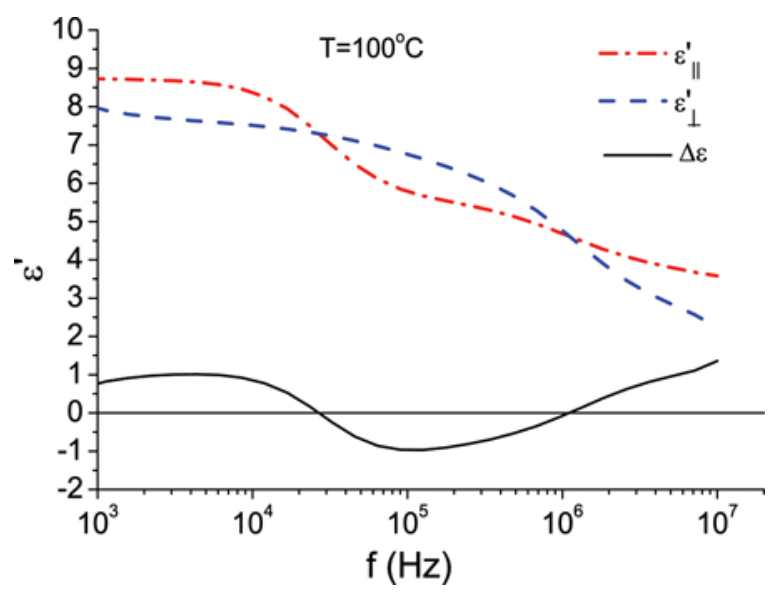

Figure 5. Frequency dependence of the dielectric constants, $\varepsilon_{\perp}$ and $\varepsilon_{\|}$measured in correspondingly planar $\left(\varepsilon_{\perp}\right)$ and homeotropic $\left(\varepsilon_{\|}\right)$cells and their difference $\Delta \varepsilon=\varepsilon_{\|}-\varepsilon_{\perp}$. (Figure appears in color online.) 
negative $\Delta \epsilon$ at high frequency assists to switch to normally OFF state. The main limitation of this control mode is relatively high power consumption to capacitive load at such frequencies.

\section{Conclusions and Perspectives}

The studied bent-core nematic material C6-BAN shows a number of interesting phenomena in dielectrics and electrooptics due to the existence of microscopic polar cybotactic clusters. An application of electric field aligns the polar axis of randomly distributed clusters and therefore induces macroscopic biaxiality. The electro-optic switching is shown to occur via the rotation of the short molecular axes. Such switching can be exploited for applications due to fast $(\sim 1 \mathrm{~ms})$ field-induced switching between the uniaxial and biaxial states thus leading to a new concept for the electrooptic switching in Liquid Crystals.

\section{Acknowledgment}

The authors thank the EU Grant No. FP7-216025 BIND and SFI Grant No. RFP 06/RFP/ENE039 for funding this work.

\section{References}

[1] Freiser, M. J. (1970). Phys. Rev. Lett., 24, 1041.

[2] Yu, L. J., \& Saupe, A. (1980). Phys. Rev. Lett., 45, 1000.

[3] Chandrasekhar, S., Raja, V. N., \& Sadashiva, B. K. (1990). Mol. Cryst. Liq. Cryst. Letter Section, 65.

[4] Malthele, J., Liebert, L., Levelut, A-M., \& Galerne, Y. (1986). Acad, C. R., Sci. Paris, 303, 1073.

[5] Shenouda, G. I., Shi, Y., \& Neubert, M. (1994). Mol. Cryst. Liq. Cryst., 257, 209.

[6] Hughes, J., et al. (1997). J. Chem. Phys., 107, 9252.

[7] Severing, K., \& Saalwachter, K. (2004). Phys. Rev. Lett., 92, 125501.

[8] Merkel, K., et al. (2004). Phys. Rev. Lett., 93, 237801.

[9] Neupane, K., et al. (2006). Phys. Rev. Lett., 97, 207802.

[10] Madsen, L. A., Dingemans, T. J., Nakata, M., \& Samulski, E. T. (2004). Phys. Rev. Lett., 92, 145505.

[11] Acharya, B. R., Primak, A., Dingemans, T. J., Samulski, E. T., \& Kumar, S. (2003) Pramana J. Phys., 61, 231; Acharya, B. R., Primak, A., \& Kumar, S. (2004). Phys. Rev. Lett., 92, 145506.

[12] Prasad, V., et al. (2005). J. Am. Chem. Soc., 127, 17224; Prasad, S. K., et al. (2005). Mol. Cryst. Liq. Cryst., 437, 211.

[13] Wensink, H. H., Vroege, G. J., \& Lekkerkerker, H. N. W. (2002). Phys. Rev. E, 66, 041704.

[14] Teixeira, P. I. C., Osipov, M. A., \& Luckhurst, G. R. (2006). Phys. Rev. E, 73, 061708.

[15] Allender, D., \& Longa, L. (2008). Phys. Rev. E, 78, 011704.

[16] Bates, M. A., \& Luckhurst, G. R. (2005). Phys. Rev. E, 72, 051702.

[17] Pelaez, J., \& Wilson, M. R. (2006). Phys. Rev. Lett., 97, 267801.

[18] Vanakarasa, A. G., \& Photinos, D. J. (2008). J. Chem. Phys., 128, 154512.

[19] de Vries, A. (1970). Mol. Cryst. Liq. Cryst., 10, 219.

[20] Stojadinovic, S., Adorjan, A., Sprunt, S., Sawade, H., \& Jakli, A. (2002). Phys. Rev. E, 66, 060701.

[21] Liao, G., et al. (2005). Phys. Rev. E, 72, 021710. 
[22] Kovalenko, L., et al. (2005). Liq. Cryst., 32, 857.

[23] Stannarius, R., Eremin, A., Tamba, M.-G., Pelzl, G., \& Weissflog, W. (2007). Phys. Rev. E, 76, 061704.

[24] Lee, J., et al. (2007). J. Appl. Phys., 101, 034105.

[25] Görtz, V., Southern, C., Roberts, N. W., Gleeson, H. F., \& Goodby, J. W. (2009). Soft Matter, 5, 463.

[26] Francescangeli, O., et al. (2009). Adv. Funct. Mater., 19, 2592.

[27] Nagaraj, M., et al. (2010). Appl. Phys. Lett., 96, 011106.

[28] Le, K. V., et al. (2009). Phys. Rev. E, 79, 030701. 